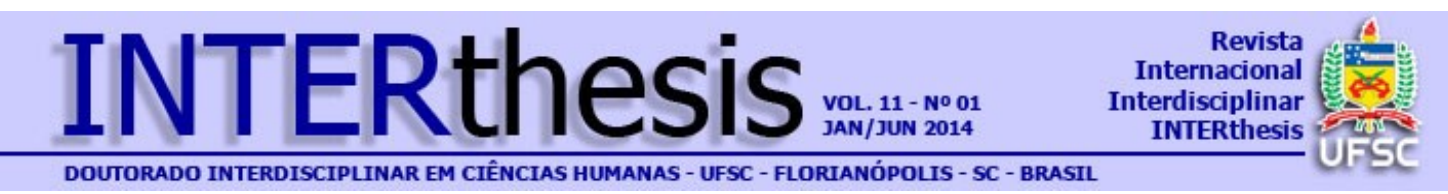

\title{
ANÁLISE DE REDE SOCIAL ${ }^{1}$
}

Carlos Leonardo Kelmer Mathias ${ }^{2}$

\section{Resumo:}

Em linhas gerais, o artigo tem por escopo empreender um debate historiográfico acerca da metodologia de análise de rede social. Mais do que responder a perguntas utilizando tal metodologia, o artigo busca introduzir o historiador à bibliografia fundadora das discussões sobre a análise de rede social. Comumente empregada por sociólogos em estudos atrelados à sociometria, desde a publicação do célebre artigo de John Barnes em 1954, a análise de rede social é uma metodologia pouco difundida entre os historiadores brasileiros. Nesse sentido, 0 texto se propõe realizar um breve debate entre as principais linhas interpretativas da análise de rede social, visando introduzir o historiador assim na metodologia em si, como na bibliografia que serviu de base das discussões atinente ao tema. Para tanto, o texto inicia com uma introdução acerca da análise de rede social para, em seguida, empreender uma discussão mais precisa sobre o tema. Por fim, o artigo esboça algumas das principais críticas sofridas pela metodologia em questão.

Palavras-chave: Análise de rede social. Debate historiográfico. Metodologia. Teoria. História.

\section{INTRODUÇÃO}

A análise de rede social se volta para o estudo e a para compreensão dos diferentes tipos de interação/comportamento observados entre indivíduos, empresas ou mesmo países. Caudatária de correntes de pensamento próprias à antropologia, psicologia, sociologia e matemática, a teoria das redes admite que o comportamento dos indivíduos de um grupo e sua estrutura se realizam no âmbito do espaço social formado pelo próprio grupo e seu entorno. Desse modo, as relações firmadas por tais indivíduos podem ser analisadas a partir de procedimentos matemáticos. Imbuídos dessas considerações, ao longo das décadas de 1930, 1940 e 1950, vários psicólogos utilizaram a teoria dos grafos para entender como a estrutura

\footnotetext{
${ }^{1}$ Esta pesquisa é financiada pela FAPERJ e pelo CNPq.

${ }^{2}$ Doutor em História pela Universidade Federal do Rio de Janeiro. Professor adjunto da Universidade Federal Rural do Rio de Janeiro, Três Rios, RJ, e pesquisador da Universidade Federal do Rio de Janeiro, Rio de Janeiro, RJ, Brasil. E-mail: clkmathias@uol.com.br
}

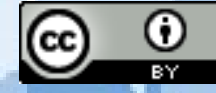

Esta obra foi licenciada com uma Licença Creative Commons - Atribuição 3.0 Não Adaptada. 
social de um grupo afeta o comportamento individual (LOZARES, 1996, p. 104-106, SCOTT, 1991). ${ }^{3}$

Malgrado o peso das teorias dos grafos e do equilíbrio estrutural da psicologia social, comumente se aceita a sociometria de Jacob Moreno como a base e a origem da análise de rede social em função das possibilidades oriundas da representação gráfica das relações entre os indivíduos. Nesse sentido, destaca-se o papel desempenhado pela sociologia estrutural, cujo enfoque percebe as "limitações e oportunidades dos atores mais como um efeito de sua conduta do que das normas culturais e outros elementos subjetivos" (SANTOS, 2003, p. 3-4). Ainda no que toca à perspectiva estrutural-funcionalista, Max Gluckman exerceu forte influência nos estudos de redes sociais. Ao sublinhar a relevância do conflito, mais do que a coesão, como fator de manutenção e transformação dos grupos sociais, o autor qualificou as redes relacionais como passíveis de serem analisadas por técnicas e conceitos específicos da sociologia com base na teoria do conflito (LOZARES, 1996, p. 105).

Entusiasta dos escritos de Harrison White, ${ }^{4}$ Peter Blau, ao defender que a estrutura social se formula em termos da alocação populacional nas diferentes posições sociais que refletem e intervêm nas relações dos indivíduos uns com os outros, definiu a macroestrutura das sociedades "como um espaço multidimensional de posições sociais entre as quais se distribuem as pessoas e que afetam suas relações sociais". Por outro lado, notou que tal conceitualização induz a homologação da macroestrutura por intermédio da microestrutura das relações entre os indivíduos. Nessa esteira, o nível macro deve dar conta tanto das inúmeras relações pessoais de uma sociedade ou comunidade, como das múltiplas posições ocupadas por essas pessoas (BLAU, 2003, p. 273, LAUMANN; MARSDEN; GALASKIEWICZ, 1977, LAUMANN; PAPPI, 1973).

Para Blau (2003), a investigação microestrutural, que se originou na tradição sociométrica de Moreno, redundou em três enfoque distintos: a teoria dos grafos, a análise de rede e os modelos de bloco. Em seu entender, a teoria dos grafos se vale

\footnotetext{
${ }^{3}$ Consoante Lozares (1996, p. 114), a "a teoria dos grafos e sua representação forneceu não só uma forma de visualização, e com isso uma certa familiaridade e popularidade à teoria de redes, mas tomada como teoria matemática proporcionou também conceitos e teoremas para muitos dos indicadores utilizados nas redes sociais".

${ }^{4}$ Trabalhando com modelos algébricos da teoria dos grafos e com técnicas analíticas como a escala multidimensional, White defende a análise de rede enquanto um método inerente ao estruturalismo, com especial destaque para as regras de conduta impostas aos atores pelas condicionantes sociais (WHITE, 1963, WHITE; BOORMAN; BREIGER, 1976, p. 730-780).
}

R. Inter. Interdisc. INTERthesis, Florianópolis, v.11, n.1, p. 131-146, Jan./Jun. 2014 
de "pressupostos psicológicos e princípios matemáticos para estabelecer proposições sobre as configurações dos vínculos que possuem mais probabilidade de se produzirem". ${ }^{5}$ Por seu turno, a análise de redes trata das ligações entre os indivíduos, sendo que o estudo das microestruturas assentadas nesses indivíduos se justapõem ao estudo macrossociológico das posições e dos conjuntos sociais. Por fim, os modelos de bloco dividem um grupo em blocos de indivíduos com posições estruturalmente equivalentes, definidas a partir da semelhança dos vínculos firmados entre pessoas pertencentes a diferentes blocos, o que equivale a dizer que um "bloco não é necessariamente um subgrupo de indivíduos que tem vínculos diretos entre si” (BLAU, 2003, p. 273-274). Consoante José Beunza, um dos historiadores pioneiros a trabalhar com análise de redes sociais, entre o fim da Segunda Guerra Mundial e a década de 1970, a história social foi, na realidade, uma história socioeconômica em que os grupos sociais eram definidos por critérios econômicos e por suas posições na esfera da produção. Nas décadas de 1980 e de 1990, tal cenário sofreu fortes mudanças com a introdução do estudo da ação social a partir da inserção dos atores em redes relacionais (BEUNZA, 1996, p. 14-16).

O presente artigo tenciona apresentar as principais características da análise de rede social. Na medida em que a análise de rede sociais foi influenciada tanto pela perspectiva macroestrutural, como pela micro, o texto intentará correlacionar ambas as visões.

\section{ANÁLISE DE REDE SOCIAL}

A despeito das várias correntes que marcam os estudos atinentes às redes sociais, usualmente considera-se John Barnes como o primeiro autor a oferecer uma definição mais sistemática de rede social orientada para a compreensão da lógica de funcionamento social à vista do estudo das interações estabelecidas entre os indivíduos. Em conformidade com o autor, rede é um campo social no qual cada sujeito está em contato com outro sujeito, podendo haver alguns deles em contado mútuo e outros não. Nas palavras de Barnes (2003): "cada pessoa tem uma série de amigos e esses amigos têm seus próprios amigos, alguns dos quais se conhecem entre si e outros não". O pioneirismo da definição proposta pelo autor, cujo texto

${ }^{5}$ Acerca da teoria dos grafos conferir Harary, Norman e Cartwright (1965).

R. Inter. Interdisc. INTERthesis, Florianópolis, v.11, n.1, p. 131-146, Jan./Jun. 2014
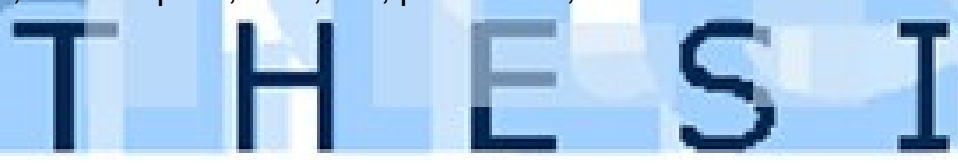
data de 1954, pode ser atestado na passagem a seguir: "a imagem que tenho na cabeça está formada por um conjunto de pontos, alguns dos quais estão conectados por linhas. Os pontos da imagem são pessoas e, em ocasiões, grupos, e as linhas indicam quais pessoas interagem mutuamente" (BARNES, 2003, p. 127). Precursora, a proposta de Barnes apontou caminhos para o refinamento da noção de rede. Em 1969, Mitchell estreitou a relação entre a representação gráfica de rede - tal qual observada por Barnes - e sua aplicação na análise social. Consoante o autor, rede é um conjunto específico de vínculos instituído em um conjunto definido de pessoas - com a propriedade adicional de que as características desses vínculos podem ser usadas para interpretar o comportamento social das pessoas implicadas. A concordar com Pilar Ponce Leiva, essa é a definição mais usual para o conceito de rede (LEIVA, 2008, p. 20). ${ }^{7}$

A par a prestimosidade das variantes oriundas das ideias anteriores, ${ }^{8}$ o ponto a assinalar é que Barnes e Mitchell influenciaram a maioria dos autores que pensaram rede social. Em 1989, Félix Santos (1989, p. 139), discutindo o impacto da teoria dos grafos no estudo das conexões sociais, definiu rede como "uma série de pontos vinculados por uma série de relações que cumprem determinadas propriedades", ou seja, "é um conjunto de relações no qual as linhas que conectam os diferentes pontos têm um valor concreto, seja este numérico ou não" (SANTOS, 1989, p. 139). A contribuição do autor repousa no fato de que a rede se torna passível de quantificação por intermédio das ligações firmadas pelos nós que concorrem para formar a rede em si. ${ }^{9}$ Três anos mais tarde, Freeman, na esteira de Santos, atrelou rede a procedimentos metodológicos: "coleção mais ou menos precisa de conceitos e procedimentos analíticos e metodológicos que facilita a coleta

\footnotetext{
${ }^{6}$ Texto original de 1954.

${ }^{7}$ Acerca da definição de Mitchell cf. Mitchell (1969, p. 5).

8 Jeremy Boissevain utiliza a noção de coalizão como forma de compreender as relações sociais empreendidas pelos indivíduos com vistas à realização de seus objetivos. Tais coalizões, de caráter temporário, teriam suas existências condicionadas não apenas aos objetivos dos sujeitos que as compõem, como também às relações por eles firmadas, o que daria a essas coalizões um caráter instável - pois com o tempo os objetivos mudariam, recursos variariam e as relações entre pessoas seriam reconfiguradas. Cf. Boissevain (2003, p. 147-183). François Lorrain e Harrison White substituíram a noção de rede pela de categoria. Os pontos representados nas redes passariam de nós para objetos, de modo que uma categoria seria composta por objetos, morfismo (ligações indiretas entre objetos) e concatenação de morfismo (representação gráfica de um morfismo: $a \rightarrow b$ e $b \rightarrow c$, de modo a haver um morfismo entre a e c de cuja redução se teria a concatenação $a \rightarrow c$ ). Para os autores, à diferença da teoria dos grafos - que considera os ciclos e trajetórias concretas que vinculam nós determinados -, a noção de categoria leva em conta todos os objetos simultaneamente, sem se ater à classificação de trajetórias em tipos conforme os vínculos concatenados. Cf. Lorrain e White (2003, p. 71-117).

${ }_{9}^{9}$ Acerca das ferramentas próprias para análise de rede cf. Hanneman (2001).
} 
de dados e o estudo sistemático de pautas de relações sociais entre as pessoas" (FREEMAN, 1992, p. 12 apud LOZARES, 1996, p. 108).

Desde então, as definições de redes sociais ora foram remetidas aos autores acima - com especial enfoque em Barnes e Mitchell -, ora denotaram natureza tautológica. A título de exemplo, Charles Kadushin percebe rede social como um conjunto de relações aptas a serem mapeadas (descrição de relações entre os nós). Em seu entendimento, para que uma rede se configure é necessário que haja um fluxo entre os nós (KADUSHIN, 2004, p. 3). Outros autores preferiram apontar características e variações nas nomenclaturas de rede. Leiva (2008) chamou atenção para o fato de que as redes podem sofrer mudanças em suas configurações ao longo do tempo: "as redes, longe de serem estáticas, confiáveis e douradoras estão sujeitas a mudanças e contingências que nos informam sobre sua vulnerabilidade". José Benza e Oihane Korta trabalharam com a noção de rede egocentrada, ou seja, o conjunto de pessoas com as quais um sujeito está relacionado direta ou indiretamente. Segundo os autores: "esta rede não é algo fechado nem completo na medida em cada um desses indivíduos mantém, por sua vez, relações com outras pessoas que não interferem nessa rede egocentrada e que, portanto, escapam à nossa percepção" (LEIVA, 2008, p. 30, BEUNZA; KORTA, 2010, p. 48).

Charles Kadushin admite que, afora as redes egocentradas, existem as redes sócio-centradas e os sistemas abertos. Acerca da primeira, essa seria uma rede configurada pela restrição espacial de seus integrantes (alunos em uma sala de aula, por exemplo). No que toca à segunda - redes mais interessantes e difíceis de estudar - elimina-se a fronteira espacial e restringe um grupo a partir de características em comuns (elite política, empresas que fabricam dado tipo de mercadoria, pessoas que adotam práticas semelhantes de ação/conduta, etc.) (KADUSHIN, 2004, p. 4). Ainda no que tange à classificação reticular, Carlos Lozares apontou que as redes podem ser institucionais, reguladas ou informais, permanentes ou passageiras, em processo ou consumadas, direcionadas ou não, superficiais ou profundas e conscientes ou inconscientes (LOZARES, 1996, p. 109110).

Na medida em que a análise de rede social versa, fundamentalmente, sobre os vínculos firmados entre pessoas, muitos estudiosos se debruçaram no desenvolvimento de noções voltadas precisamente para a melhor compreensão

R. Inter. Interdisc. INTERthesis, Florianópolis, v.11, n.1, p. 131-146, Jan./Jun. 2014
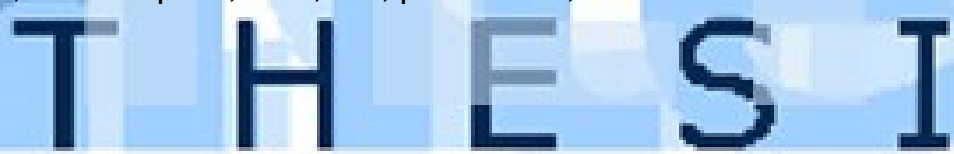
desses vínculos. Dentre tais pesquisadores, Mark Granovetter foi, sem dúvida, aquele cujas ideias mais influenciaram as discussões referentes às ligações reticulares. Para o autor, em toda rede há dois tipos de vínculos: fortes e fracos. Os primeiros seriam aqueles que expressam maior proximidade entre os indivíduos, sendo que os segundos denotam dado grau de afastamento social. A título de exemplo, a ligação entre amigos é um laço forte e a ligação entre conhecidos um laço fraco, de modo que para determinar a força de um laço é necessário se ter em conta seu tempo de duração, a intensidade emocional, a intimidade (confiança mútua) e os serviços recíprocos expressados pelo vínculo - donde cada um desses aspectos, embora interligados, são independentes entre si. Todas essas características estão mais acentuadas nos laços fortes do que nos fracos (GRANOVETTER, 1973, p. 1361-1362).

Tomando os grupos A e B formados pelos círculos de amigos íntimos de, respectivamente, a' e b', e admitindo que esses dois indivíduos são conhecidos um do outro, tem-se que A e B não estariam conectados senão por a' e b' que, entre si, firmam uma ligação fraca, pois conhecidos e não amigos. A importância dos laços fracos repousa na possibilidade de oferecerem aos indivíduos acesso a informações/oportunidades que não teriam estando limitados a seus grupos íntimos, regidos por laços fortes. Nas palavras de Granovetter (2003, p. 197-205): "os indivíduos com poucos laços fracos estariam privados das informações procedentes de partes distantes do sistema social e acessariam só as limitadas notícias e opiniões de seus amigos íntimos". Por outro lado, sem embargo de os laços fracos proporcionarem acesso a informações e recursos inexistentes nos círculos sociais de laços fortes, esses últimos têm mais motivação para viabilizar ajuda, estando, normalmente, disponíveis com mais facilidade, pois a natureza de seus vínculos expressam valores como, por exemplo, amizade (GRANOVETTER, 2003, p. 197205). ${ }^{10}$

Uma vez que a análise de rede social trata, em grande medida, da interação social observada entre os indivíduos, pode-se afirmar que ela comporta dupla

\footnotetext{
${ }^{10}$ Charles Kadushin elenca três críticas à noção de laço fraco, quais sejam: a) a definição em si de laço fraco é pouco precisa; b) a ideia principal não aborda uma explicação conceitual, mas tão somente expressa a possibilidade da ocorrência de uma ponte entre segmentos da rede; c) a condução de informação não necesariamente ocorre, pois pode haver um custo ou uma condição para tal fluxo - alguém poderia não querer pasar a informação adiante, por exemplo (KADUSHIN, 2004, p. 30-31). Para José Beunza, assim como os laços fracos, os fortes igualmente servem à propriedade de conduzir informação pela rede (BEUNZA, 2010, p. 299).
}

R. Inter. Interdisc. INTERthesis, Florianópolis, v.11, n.1, p. 131-146, Jan./Jun. 2014 
interpretação: ora se admite que a ação social é influenciada (ou condicionada, dependendo da abordagem) direta ou indiretamente pela estrutura social, ora se advoga que é a ação social a promotora das modificações na estrutura social. Por um lado, o sujeito está imerso em uma rede de relações sociais cuja estrutura influi/determina sua conduta. Por outro, o sujeito poderia manipular sua rede com vistas à realização de seus objetivos. Em resumo, a primeira abordagem versa sobre a influência da estrutura reticular na conduta social do ator e a segunda diz respeito à manipulação da rede pelo ego em benefício próprio (SANTOS, 2003, p. 6-11). ${ }^{11}$

A maioria das pesquisas acerca de redes sociais em algum momento comparam "a rede ordenada pela cultura e pelo sistema social com redes criadas e negociadas por pessoas no processo de tentar gerenciar e trabalhar o sistema" (KADUSHIN, 2004, p. 23-24). Logo, muitos autores fizeram uso da análise de rede social em função de seus descontentamentos com os modelos estruturais. Tal insatisfação regeu uma revisão de conceitos e pesquisas voltados para análise das relações sociais vis-à-vis entre indivíduos. Em boa verdade, a metodologia de rede social suplementa, mais do que suplanta, a perspectiva estrutural. ${ }^{12}$ Karen Cook (2003) propôs um meio termo entre essas duas abordagens ao ressaltar a necessidade de se analisar a relação entre microprocessos e macroestruturas por intermédio de uma ótica que considera a conjugação de ambos. Em suas palavras: "se a teoria deve incluir os atores e as estruturas, é necessário empreender um exame mais completo das motivações que geram os processos de intercâmbio" (COOK, 2003, p. 479-480, 489).

\footnotetext{
${ }^{11}$ De acordo com Kenneth Frank - autor que defende a primazia da estrutura sobre os indivíduos sociólogos e psicólogos sociais argumentam que as pessoas são muito influenciadas pelos membros de seus grupos primários. Em outra via, antropólogos defendem que grupos primários são importantes para se compreender os atores em seus contextos sociais. Afirma que modelos de interação estão ligados à base de conhecimento dos atores e de suas ações daí resultantes, sendo que membros de um grupo coeso são suscetíveis a partilhar ideias e apresentar ações similares conforme a natureza de suas interações (FRANK, 1995, p. 28). No que respeita à definição de estrutura social com vistas para o estudo de rede social, Peter Blau entende que estrutura social se refere à distribuição de uma população entre diferentes posições sociais que, por sua vez, refletem e afetam as relações das pessoas entre si. Tal estrutura estaria arraigada nas distinções sociais produzidas pelos indivíduos tantos em suas relações baseadas em suas funções sociais, como em suas associações sociais (BLAU, 2003, p. 272-273). Pilar Ponce Leiva afirma que nas sociedades de Antigo Regime - em que boa parte das relações entre os indivíduos, além de herdadas (principalmente na esfera familiar), eram regidas por normas -, a não aceitação das obrigações fruto do emaranhado relacional poderia acarretar severas consequências, com que então toda escolha implicava repercussões e consequências (LEIVA, 2008, p. 30).

${ }_{12}$ A título de exemplo, Mitchell cita o próprio Barnes, autor que teria desenvolvido a noção de rede social a partir de dados empíricos de modo a permitir o preenchimento da lacuna entre o quadro estrutural e suas observações de campo (MITCHELL, 1974, p. 279-282).
}

R. Inter. Interdisc. INTERthesis, Florianópolis, v.11, n.1, p. 131-146, Jan./Jun. 2014 
Posto que noções como categoria social, grupo social, classe e estratos têm valor relativo, insuficiente e muitas vezes enganoso para a análise dos atores e da ação social, faz-se mister, em termos de rede social, uma abordagem relacional que transcenda a classificação social. Assim, Beunza se questiona acerca de "como integrar o microcosmos e o macrocosmos? Como ter em conta o indivíduo, a multidão de atores individuais, sem perder de vista a configuração coletiva da sociedade, as estruturas sociais e os grandes processos de mudança históricos?". No seu entender, os vínculos sociais devem atuar como suporte básico da ação na sociedade. Atendo-se a uma sociedade de Antigo Regime, o autor sustenta que, para analisar o quão as relações pessoais estavam reguladas por vínculos e normas ou se construíam a partir da ação individual, é necessário estudar trajetórias de vida no contexto das relações sociais a serem analisadas. Mais de perto, deve-se voltar a atenção para as relações sociais estabelecidas pelos atores ao longo do tempo (BEUNZA, 1996, p. 14-18, BEUNZA, 2010, p. 284-286). ${ }^{13}$

De acordo com Peter Blau, não seria possível a elaboração de uma teoria sociológica unificada que incluísse explicações acerca da importância tanto das macroestruturas, como dos microprocessos para a vida social. O principal empecilho para a empresa repousaria no fato de que esses dois campos tratam de aspectos sociais distintos demandando, destarte, distintas ferramentas analíticas. As unidades de análise são diferentes - indivíduos, a nível micro, e populações, a macro -, do mesmo modo que os conceitos e as variáveis - atributos dos atores no campo micro e propriedades oriundas das estruturas populacionais no macro. Exemplificando: "indivíduos podem ser ricos ou pobres, mas só as coletividades podem exibir uma maior ou menor desigualdade econômica" (BLAU, 1987, p. 83-100).

Em sentido contrário, Karen Cook argumenta a favor da correlação acima por intermédio da noção de rede de intercâmbio, caudatária da teoria do intercâmbio social. Consoante a autora, as proposições responsáveis pelo estreitamento da ideia de rede com a natureza da dependência dos recursos nas redes de intercâmbio estão assentadas no resultado dos diferentes acessos, que têm os atores aos recursos que valorizam. Tal dependência está, pois, relacionada à distribuição de poder na rede. No que toca à instrumentalização analítica das redes sociais, o poder está profundamente correlacionado com a ideia de centralidade, com que então

\footnotetext{
${ }^{13}$ Vale salientar que para Miceli $(2008$, p. 9) "o modo pelo qual as pessoas percebem suas redes de relações pode ser tanto ou mais importante que os vínculos realmente existentes".
}

R. Inter. Interdisc. INTERthesis, Florianópolis, v.11, n.1, p. 131-146, Jan./Jun. 2014 
quanto mais central um nó, mais poderoso ele tende a ser. Assim, o grau de compromisso dos indivíduos com dada rede varia de acordo com: a) o equilíbrio de poder na rede; e b) a dificuldade (ou facilidade) dos sujeitos em encontrar outras pessoas que thes viabilizem a concretização de seus intentos. Em resumo, Cook afirma ser possível promover a integração entre os microprocessos e a macroestrutura por intermédio da noção de rede de intercâmbio que, por seu turno, se vale dos conceitos de centralidade e de poder como ferramentas privilegiadas nesse processo (COOK, 2003).

Do posto, e em termos metodológicos e analíticos, Carlos Lozares aponta como os princípios centrais das redes sociais: a) os atores e suas ações não são unidades autônomas, mas interdependentes; b) os laços relacionais entre os atores implicam transferências de recursos materiais e imateriais; c) as estruturas das relações encerram o entorno que proporcionam oportunidades ou coagem a ação individual; e d) a rede identifica a estrutura social como padrão de relação entre atores (LOZARES, 1996, p. 110-111). Em respeito à localização dos nós face ao ego, Boissevain (1968, p. 542-556) distingue três zonas: a) zona íntima, que englobaria os nós mais próximos do ego; b) zona efetiva, que conglomeraria nós não tão próximos do ego; e c) zona estendida, que reúne os nós sem ligação direta com o ego, mas cujo acesso poderia se dar através de ligações indiretas. Não vem à pelo arrolar as inúmeras ferramentas analíticas no trato com redes sociais. Não obstante, faz-se necessário apresentar algumas das mais relevantes: o tamanho da rede (número de nós que a compõem); a natureza dos vínculos (parentesco, amizade, etc.); a frequência das relações (número de ligações); a densidade (porcentagem entre o total de ligações da rede frente ao total possível) $;{ }^{14}$ a durabilidade da rede e de cada vínculo, a classe (número de vínculos de nó); a centralidade (um nó é tanto mais central quanto mais vínculos possui); e os grupos e subgrupos existentes na rede. ${ }^{15}$ Malgrado as inúmeras contribuições ofertadas pela análise de rede social, não é de todo descabido expor algumas das críticas a ela direcionadas.

${ }^{14}$ Para uma discussão específica sobre esse importante aspecto de rede conferir Cruz e Verd (2011, p. 181-203).

${ }^{15}$ Acerca dessas ferramentas analíticas cf. Hanneman (2001).

R. Inter. Interdisc. INTERthesis, Florianópolis, v.11, n.1, p. 131-146, Jan./Jun. 2014
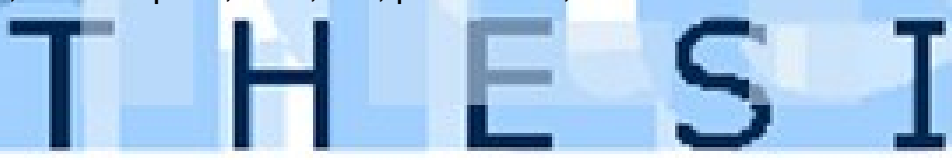


\section{CRÍTICAS À ANÁLISE DE REDE SOCIAL}

Com a difusão da análise de rede social, teve fez e efeito a eclosão de duas tendências divergentes acerca da sua recepção entre a comunidade acadêmica, a saber: a) rechaçou-se seus benefícios por não se compreender a base técnica inerente a tal ferramenta e b) essa mesma base se converteu em um aparato de validação supostamente autônomo e imune aos exames pelos quais necessariamente devem passar "perspectivas menos dependentes de uma linguagem fortemente operacionalizada" (MICELI, 2008, p. 2). Nesse sentido, o próprio desenvolvimento de técnicas heurísticas que se prestam à maximização do emprego da análise de rede social como uma ferramenta voltada para a explicação e compreensão das sociedades restou por concorrer ora para descredenciá-la, ora para legitimá-la.

Uma das principais críticas à análise de redes sociais repousa no processo de compilação dos dados utilizados para a construção da rede. Segundo Lozares (2005, p. 9):

Às vezes, a análise de rede social se apresenta com uma caixa de ferramentas de natureza técnico-formal e/ou gráfica na busca pragmática e eficaz de resultados sem uma razoável reflexão sobre as condições e situação de recolhimento de informação, sobre a natureza dos dados e sua contextualização, sobre as dimensões cognitivas, factuais, dinâmicas, simbólicas etc. que as relações sociais supõem ou sobre os campos nos quais se inserem essas relações.

Dando eco às considerações de Lozares, Miceli observou quão rarefeitos foram os questionamentos tangentes à "arbitrariedade dos processos de seleção de dados, sobre seu alcance condicional e sobre o enorme conjunto de definições operacionais que estão controlando e habilitando a maioria dos mecanismos de inferência aos quais se apela" (MICELI, 2008, p. 4). Em resumo, critica-se a negligência metodológica quer no trato empírico, quer em âmbito analítico, por parte dos pesquisadores que recorrem às redes sociais enquanto ferramenta de estudo das sociedades em seus diversos âmbitos, assim macros, como micros. Parte desses apontamentos provém exatamente do léxico atinente às redes sociais. Atribui-se à especificidade desse vocabulário o fato de haver certo nível de indolência na crítica direcionada aos trabalhos de rede social, pois o emprego de

R. Inter. Interdisc. INTERthesis, Florianópolis, v.11, n.1, p. 131-146, Jan./Jun. 2014
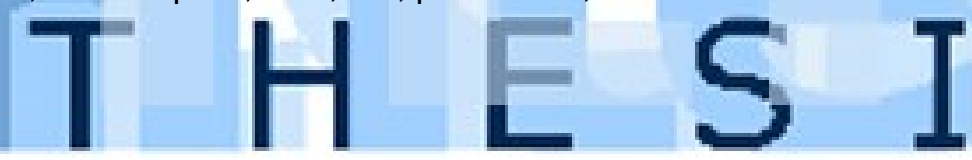
termos como ligação diática, gráfico direcionado, morfismo, clique, etc. costuma dar a impressão de que o autor é "de alguma forma um especialista perfeitamente à salvo da ignorância dos leigos". O mesmo pode ser dito acerca das representações gráficas das redes sociais (MICELI, 2008, p. 3-4). ${ }^{16}$

Redirecionando o exame para um campo mais teórico, Charles Kadushin pôs em relevo dificuldades respeitantes à percepção dos vínculos firmados entre os atores no viver em sociedade. Afora a existência de "fronteiras" no interior das sociedades responsáveis por tergiversar a identificação de vínculos sociais, há uma multiplicidade de fluxos atuantes concomitantemente nas relações entre pessoas, fluxos esses impossíveis de serem representados graficamente. Ou seja, em uma ligação de trabalho entre duas pessoas se fazem presentes emoções como amizade, indiferença, afeto, raiva, etc., em que a representação na rede de todos esses elementos é bastante difícil, quiçá impraticável. Logo, Kadushin (2004, p. 16) afirma que as redes tratam exclusivamente de relacionamentos e fluxos, sendo incompatível com sua proposta a análise dos atributos/natureza das ligações.

Especificamente no que toca ao emprego da análise de rede social na história, Pilar Ponce Leiva pondera que os historiadores carecem de embasamento teórico/metodológico na lida com as ferramentas, as possibilidades e os recursos dos estudos de rede. Afirma que muitos autores citam "como referenciais teóricos o que em realidade são casos empíricos que fazem uma nova e intuitiva utilização das fontes, introduzindo assim uma nova metodologia que, eventualmente, desemboca no desenvolvimento de um novo enfoque historiográfico". Dentre outros problemas da serventia da análise de rede no campo da história, Leiva aponta: a) a confusão entre análise de rede e outros enfoques historiográficos (a micro história, por exemplo); b) pouca acuidade no trato conceitual, resultando em um amálgama de noções como família, grupo, rede, etc.; e c) carência metodológica na seleção de fontes de pesquisa, atores a serem abordados, caracterização de vínculos, etc. Não obstante, o enfoque das redes sociais permitir analisar as margens de liberdade de atuação individual, muitos estudos levados a cabo por historiadores promoveram uma abordagem linear e causal do comportamento humano a partir da identificação da natureza das ligações. Conforme a autora, estabelecer

${ }^{16}$ Para Herrero (2000, p. 199), no que respeita às traduções do inglês para o espanhol as imprecisões e ambiguidades da terminologia de redes se originam da inexistência de um marco teórico claro para o estudos das redes sociais.

R. Inter. Interdisc. INTERthesis, Florianópolis, v.11, n.1, p. 131-146, Jan./Jun. 2014 
vínculos entre as pessoas sem determinar suas propriedades, características, natureza ou conteúdo preciso - isto é, um uso metafórico do conceito - é, provavelmente, a característica mais habitual nos estudos históricos interessados nas redes sociais (KADUSHIN, 2004, p. 21-28).

\section{CONCLUSÃO}

O presente artigo buscou apresentar à comunidade acadêmica dos historiadores, em linhas gerais, a metodologia de análise de rede social tendo em conta os poucos trabalhos de historiadores que se valem dessa ferramenta em suas pesquisas no Brasil. Valioso instrumental metodológico-analítico, a análise de rede social se presta ao estudo tanto das sociedades como dos indivíduos em qualquer época. Na medida em que, a corrente da micro-história italiana está tão em voga nos dias atuais, acreditamos que seu emprego em conjugação com a análise de rede social poderá oferecer um importante contributo para a (re)interpretação quer da lógica de funcionamento das sociedades, quer das estratégias de ação a nível individual. Tal acréscimo é passível de ser obtido na medida em que a análise de rede social oferta uma oportunidade de compreensão da natureza das ligações sociais a nível macro e micro, concorrendo para esclarecer as estratégias e os comportamentos de indivíduos, de empresas, etc.

R. Inter. Interdisc. INTERthesis, Florianópolis, v.11, n.1, p. 131-146, Jan./Jun. 2014 


\title{
SOCIAL NETWORK ANALYSIS
}

\begin{abstract}
In general, the paper develops a historiographical debate about the methodology of social network analysis. More than responding questions using such methodology, this article tries to introduce the historian to the founder bibliography of social network analysis. Since the publication of the famous article by John Barnes in 1954, sociologists linked to sociometric studies have usually employed the social network analysis in their studies. On the other hand, this methodology is not widespread among Brazilian historians. Thus, the text undertakes a brief discussion among the main interpretative lines of social network analysis. The aim is to introduce the historian in the methodology of social network analysis and in the bibliography that formed the basis of discussions on the topic. Thus, the text begins with an introduction about the social network analysis, undertakes a more precise discussion on the topic and, in the end, outlines some of the main criticisms suffered by the methodology in question.
\end{abstract}

Keywords: Social network analysis. Historiographical debate. Methodology. Theory. History.

\section{ANÁLISIS DE REDES SOCIALES}

\section{Resumen}

En general, el artículo desarrolla un debate historiográfico sobre la metodología de análisis de redes sociales. Más que tratar de responder a preguntas, utilizando tal metodología el artículo busca introducir al historiador a la literatura fundadora de las discusiones sobre análisis de redes sociales. Comúnmente utilizada por los sociólogos en estudios sociométricos desde la publicación del famoso artículo de John Barnes en 1954, el análisis de redes sociales es una metodología poco difundida entre los historiadores brasileños. Por lo tanto, este texto propone una breve discusión de las principales líneas de interpretación del análisis de redes sociales con el fin de introducir al historiador a la metodología propiamente y a la bibliografía que sirvió de base para los debates sobre el tema. Por lo tanto, el texto comienza con una introducción del análisis de redes sociales, para después llevar a cabo una discusión más precisa sobre el tema y, finalmente, se describen algunas de las principales críticas que sufrió la metodología en cuestión.

Palabras clave: Análisis de redes sociales. Debate historiográfico. Metodología. Teoría. Historia 


\section{REFERÊNCIAS}

BARNES, J. Clase y comités en una comunidad isleña Noruega. In: SANTOS, F. R. (org.). Análisis de redes sociales: orígenes, teorías y aplicaciones. Madrid: Centro de Investigaciones sociológicas, 2003. p. 121-146.

BEUNZA, J. Solidaridades y conflictos: las relaciones personales en la construcción de economías compartidas y dinámicas duraderas". In: BEUNZA, J. M. I.; KORTA, O. O. (orgs.). Economía doméstica y redes sociales en el Antiguo Régimen. Madri: Sílex, 2010. p. 283-334.

BEUNZA, J. Comunidad, red social y élites. Un análisis de la vertebración social en el Antíguo Régimen. In: BEUNZA, J. (ogr.). Élites, poder y red social: las elites del País Vasco y Navarra em la Edad Moderna. Bilbao: Servicio Editorial-Universidad del País Vasco/EHU, 1996. p.13-50.

BEUNZA, J. M. I.; KORTA, O. O. Economía doméstica y redes sociales: una propuesta metodológica. In: BEUNZA, José María Imizcoz; KORTA, Oihane Oliveri (orgs.). Economía doméstica y redes sociales en el Antiguo Régimen. Madri: Sílex, 2010. p. 15-51.

BLAU, P. Teoría macrosociológica de la estructura social. In: SANTOS, F. R. Análisis de redes sociales: orígenes, teorías y aplicaciones. Madrid: Centro de Investigaciones sociológicas, 2003. p. 270-307.

BOISSEVAIN, J. Coaliciones. In: SANTOS, Félix Requena. Análisis de redes sociales: orígenes, teorías y aplicaciones. Madrid: Centro de Investigaciones sociológicas, 2003, p. 147-183.

BOISSEVAIN, J. The place of non-groups in the social sciences. Man, New Series, v. 3, n. 4, p. 542-556, dec. 1968. Disponível em: <http://www.jstor.org>. Acesso em: 25 jan. 2013.

COOK, K. La vinculación de actores e estructuras desde la perspectiva de las redes de intercambio. In: SANTOS, F. R. Análisis de redes sociales: orígenes, teorías y aplicaciones. Madrid: Centro de Investigaciones sociológicas, 2003. p. 478-497.

CRUZ, I.; VERD, J. M. Densidad, classe social y apoyo expersivo. REDES - revista hispana para el análisis de redes sociales, v. 20, n. 8, p. 181-203, jun. 2011.

R. Inter. Interdisc. INTERthesis, Florianópolis, v.11, n.1, p. 131-146, Jan./Jun. 2014
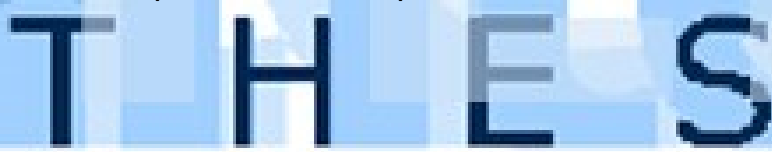
Disponível em: <http://revistes.uab.cat/redes/article/view/412/292>. Acesso em: 25 jan. 2013.

FRANK, K. Identifying cohesive subgroups. Social networks, n. 17, p. 27-50. 1995.

GRANOVETTER, M. La fuerza de los lazos débiles: revisión de la teoría reticular. In: SANTOS, F. R. (org.). Análisis de redes sociales: orígenes, teorías y aplicaciones. Madrid: Centro de Investigaciones sociológicas, 2003. p. 196-230.

GRANOVETTER, M. The strength of weak ties. American journal of sociology, v. 78, n. 6, p. $1360-1380.1973$.

HANNEMAN, R. Introduction to social network methods. University of Califórnia: Riverside, 2001.

HARARY, F.; NORMAN, R.; CARTWRIGHT, D. Structural models: an introduction to the theory of directed graphs. New York: John Wiley \& Son, 1965.

HERRERO, R. La terminologia del análisis de redes. Política y sociedade, n. 33, p. 199-206. 2000.

KADUSHIN, C. Introduction to social network theory. Draft, p. 1-60, fev. 2004. Disponível em:

<http://www.communityanalytics.com/Portals/0/Resource Library/Social\%20Network \%20Theory Kadushin.pdf>. Acesso em: 15 jan. 2013.

LAUMANN, E.; MARSDEN, P.; GALASKIEWICZ, J. Community-elite influence structures: extension of a network approach. The American Journal of Sociology, n. 3 , v. 83 , p. 594-631. 1977.

LAUMANN, E.; PAPPI, F. U. New directions in the study of community elites. American Sociological Review, n. 2, v. 38, p. 212-230. 1973.

LEIVA, P. P. Redes sociales y ejercicio del poder en la América Hispana: consideraciones teóricas y propuesta de análisis. Revista Complutense de História de América, v. 34, p. 15-34. 2008.

R. Inter. Interdisc. INTERthesis, Florianópolis, v.11, n.1, p. 131-146, Jan./Jun. 2014
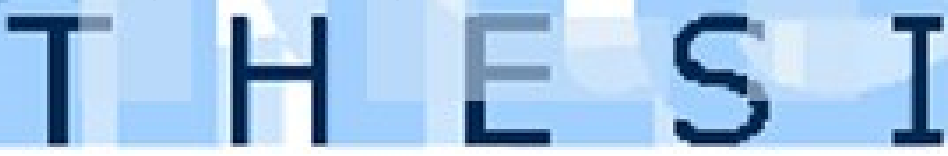
LORRAIN, F.; WHITE, H. La equivalencia estructural de los individuos en las redes sociales. In: SANTOS, F. R. Análisis de redes sociales: orígenes, teorías y aplicaciones. Madrid: Centro de Investigaciones sociológicas, 2003. p. 71-117.

LOZARES, C. Bases socio-metodológicas para el análisis de redes sociales.

Empiria: revista de metodología de ciencias sociales, n. 10, p. 9-35, jul.-dic. 2005.

LOZARES, C. La teoría de redes sociales. Papers, n. 48, p. 103-126. 1996.

MICELI, J. Los problemas de validez en el análisis de redes sociales: algunas reflexiones integradoras. REDES - revista hispana para el análisis de redes sociales, v. 14, n. 1-45, jun. 2008. Disponível em: < http://revistes.uab.cat/redes/article/view/117/119>. Acesso em: 25 jan. 2013.

MITCHELL, J. C. Social networks. Annual review of anthropology, v. 3, p. 279299. 1974.

MITCHELL, J. C. The Concept and Use of Social Networks. In: MITCHELL, J. C. (ed.). Network Analysis: studies in human interaction. Paris: Mouton, 1969. p. 1-50.

SANTOS, F. R. Orígenes sociales del análisis de redes. In: SANTOS, F. R. (org.). Análisis de redes sociales: orígenes, teorías y aplicaciones. Madrid: Centro de Investigaciones sociológicas, 2003. p. 4-12.

SANTOS, F. R. El concepto de red social. REIS - Revista española de investigaciones sociológicas, n. 48, p. 137-152. 1989

SCOTT, J. Social network analysis. Londres: Sage, 1991.

WHITE, H. An Anatomy of kinship. Englewood Cliffs, New Jersey: Prentice-Hall, 1963.

WHITE, H.; BOORMAN, S.; BREIGER, R. Social structure from multiple networks I. American Journal of Sociology, n, 81, p. 730-780. 1976.

\section{Artigo:}

Recebido em Janeiro de 2014.

Aceito em Março de 2014.

R. Inter. Interdisc. INTERthesis, Florianópolis, v.11, n.1, p. 131-146, Jan./Jun. 2014
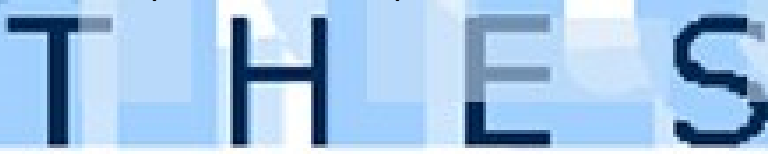